\title{
Acetylcholine Receptors in Extrajunctional Regions of Innervated Muscle Have a Slow Degradation Rate
}

\author{
M. M. Salpeter and M. Marchaterre \\ Department of Neurobiology and Behavior, Cornell University, Ithaca, New York 14853
}

\begin{abstract}
Scanning EM autoradiography was used to determine the degradation rate of extrajunctional ACh receptors (AChRs) in innervated sternomastoid muscles of the mouse. We report that in innervated muscles, extrajunctional AChRs have a slow degradation rate $\left(t_{1 / 2}, \sim 8 \mathrm{~d}\right)$, similar to that seen at the neuromuscular junction. We conclude that slowly degrading AChRs $\left(R_{s}\right)$ need not be localized at the specialized structure of the nerve-muscle junction. Degradation of extrajunctional as well as junctional AChRs may depend primarily on the state of innervation of the muscle.
\end{abstract}

It has been suggested that the degradation rate of $\mathrm{ACh}$ receptor (AChR) molecules at the neuromuscular junction (nmj) of adult muscle depends in part on whether the AChRs were synthesized in innervated or denervated muscle (Shyng and Salpeter, 1990). Whereas junctional AChRs synthesized in innervated muscle have a degradation $t_{1 / 2}$ of $\sim 8-10 \mathrm{~d}$ (which accelerates to one of $\sim 2-4 \mathrm{~d}$ after denervation) (Levitt and Salpeter, 1981; Stanley and Drachman, 1981; Brett et al., 1982; Bevan and Steinbach, 1983), AChRs synthesized after denervation degrade with a $t_{1 / 2}$ of $\sim 1 \mathrm{~d}$ not only at extrajunctional regions (literature reviewed by Fambrough, 1979), but also at the nmj (Levitt and Salpeter, 1981; Shyng and Salpeter, 1989, 1990; Shyng et al., 1991). AChR degradation may thus depend more on when the AChR is synthesized than on where it is localized. To test the extent of this conclusion, we examined the degradation rate of extrajunctional AChRs in innervated muscle.

We report that in mouse innervated sternomastoid muscle, extrajunctional AChRs degrade with an average measured halflife of 7-9 d, similar to that of the AChRs at the innervated junction. These results show that AChRs with a slow degradation rate (called $R_{s} A C h R s$ ) can be located throughout the extrajunctional muscle membrane even where the AChR binding site density has dropped to $<8$ sites $/ \mu \mathrm{m}^{2}(<4 \mathrm{AChR}$ molecules $\left./ \mu \mathrm{m}^{2}\right)$. It was previously shown that $\mathrm{R}_{\mathrm{s}} A C h R s$ are not necessarily localized at a high AChR site density (Salpeter and Harris, 1983). The present study extends this finding to even lower site densities and also shows that $R_{s} A C h R s$ nced not bc restricted to the morphologically specialized region of the $\mathrm{nmj}$. These results add to the mounting evidence derived also from

Received Mar. 7, 1991; revised July 29, 1991; accepted July 31, 1991.

We thank Maria Szabo and Peaches Bell for technical assistance, Tom Podleski for helpful discussion, and Deborah Moslehi for preparing the manuscript. This study is supported by NIH Grant GM 10422.

Correspondence should be addressed to Miriam M. Salpeter, Department of Neurobiology and Behavior, Cornell University, W113 Mudd Hall, Ithaca, NY 14853.

Copyright (C) 1992 Society for Neuroscience $0270-6474 / 92 / 120035-04 \$ 05.00 / 0$ studies on AChR channel kinetics (Brehm and Kullberg, 1987; Henderson et al., 1987; Brehm and Henderson, 1988) indicating that the distinction between junctional and extrajunctional AChRs must be reconsidered.

\section{Materials and Methods}

Specific labeling of AChRs. AChRs in innervated mouse sternomastoid muscles were labeled with ${ }^{125} \mathrm{I}-\alpha$-bungarotoxin $\left({ }^{125} \mathrm{I}-\alpha-\mathrm{BGT}\right)(3 \mu \mathrm{M})$ by topical application for $1.5 \mathrm{hr}$, as previously described (Fertuck et al., 1975). Atropine was administered $(1.8 \mathrm{mg} / \mathrm{kg}$ ) as needed during the operation to eliminate respiratory distress. The extent of saturation during a $1.5 \mathrm{hr}$ incubation period was previously judged to be $>95 \%$ (Loring and Salpeter, 1980; Shyng and Salpeter, 1989). Nonspecific binding, obtained by preincubating muscles with nonradioactive BGT for $1.5 \mathrm{hr}$ followed by ${ }^{125} \mathrm{I}-\alpha-\mathrm{BGT}$ for the same time, was subtracted from total counts to get specific binding.

Determination of distribution and degradation of extrajunctional $A C h R s$. AChR site densities and degradation rates were assessed using scanning EM (ScEM) autoradiography, since the more usual procedure of gamma counting (e.g., Berg and Hall, 1975; Levitt and Salpeter, 1981) could not unequivocally distinguish extrajunctional from junctional AChRs in innervated muscles, nor accurately detect very low levels of extrajunctional AChRs. For ScEM autoradiography, the procedure of Salpeter et al. (1988) was followed. At various times ( $3 \mathrm{hr}, 1,8$, and 16 d) after labeling with ${ }^{125} \mathrm{I}-\alpha$-BGT, animals were anesthetized and killed by intracardial perfusion with $2.5 \%$ glutaraldehyde in phosphate buffer $(0.067 \mathrm{M}, \mathrm{pH} 7.4)$. The labeled muscles were dissected from the animals, postfixed in glutaraldehyde $(2.5 \%$ in phosphate buffer for $1 \mathrm{hr}$ ), and dissociated with the $\mathrm{HCl}-\mathrm{OsO}_{4}$ method of Desaki and Uehara (1981). The dissociated fibers were placed onto ScEM stubs over double-sided scotch tape, carbon coated, and coated with stripped preformed monolayers of emulsion (IIford L4). After exposure times ranging from 30 to $60 \mathrm{~d}$, they were developed for $2 \mathrm{~min}$ with D19 at room temperature. To avoid overexposing the emulsion and yet have sufficient grains for adequate statistical sampling, the exposure times were determined to give $0.1-0.8$ grain per $\mu \mathrm{m}^{2}$ of surface area in extrajunctional regions. Grain counts, obtained as described below, were used to calculate AChR density as previously described (Fertuck and Salpeter, 1976; MatthewsBellinger and Salpeter, 1978). Values were expressed either as AChR site density (defined as the number of $\alpha$-BGT or ACh binding sites/ $\mu \mathrm{m}^{2}$ ) or as AChR molecules, which is half the site density.

Extrajunctional AChR values were obtained using two different methods. In the first method, fibers from all time points were fully scanned and neuromuscular junctions (nmjs) were located by their unique morphology. The muscle fibers were then photographed (at $2000 \times$ magnification) and contiguous montages were made up to $130 \mu \mathrm{m}$ from each junction. For each time point, micrographs were obtained from two to five fibers from each of two to four animals. Grains were counted from prints, starting $4.5 \mu \mathrm{m}$ from the visually identified morphological edge of an $\mathrm{nmj}$. [When averaging site densities over large distances along the muscle fiber, the effect of the density gradient from the $\mathrm{nmj}$ (Salpeter et al., 1988) was prevented from biasing the standard error of the mean (SEM) values as follows: average site densities were first obtained for each consecutive $5 \mu \mathrm{m}$ distance bin, and the SEM value for that distance bin was expressed as a percentage of the average. All the individual bins and their percentage SEM values were then averaged over the full distance, and the averaged SEM expressed in absolute units of site density.] 


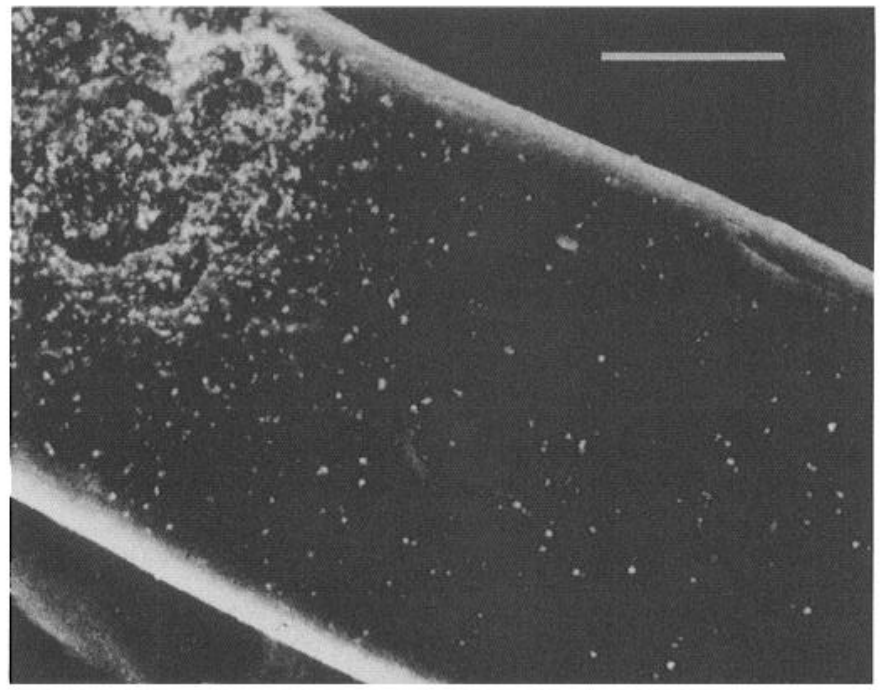

Figure 1. Sample ScEM autoradiogram with highly overexposed $\mathrm{nmj}$ (upper left) gives easy grain counting over nonjunctional regions. (The specific activity of BGT was $78 \mathrm{C} / \mathrm{mmol}$ on day of emulsion coating, and the exposure time was $58 \mathrm{~d}$.) Note the very steep gradient in the vicinity (especially within $10 \mu \mathrm{m}$ ) of the edge of the $\mathrm{nmj}$. Magnification, $1900 \times$; scale bar, $10 \mu \mathrm{m}$.

In the second method, AChRs of random extrajunctional regions were obtained by photographing muscle fiber fragments without nmjs. Ten fibers from each of two animals were analyzed for 1 and $16 \mathrm{~d}$ after labeling. To avoid needing a correction for muscle fiber curvature, grain counts in both methods were restricted to the top surface of a muscle fiber using an overlay counting grid with grid squares of $5 \times 5 \mu \mathrm{m}$. Micrographs were also taken of emulsion areas near muscle fibers for background corrections.

The measured degradation rate of the AChRs was determined by the rate of decrease in the labeled $A C h R$ site density assuming first-order exponential decays. Degradation was measured from day 1 to day 16 after labeling. The first day was omitted to avoid the frequently reported effect of a rapidly degrading component seen during this early period even at the innervated neuromuscular junction (Stanley and Drachman, 1981; Bevan and Steinbach, 1983).

\section{Results}

Figure 1 shows a sample ScEM autoradiogram used to determine the extrajunctional $\mathrm{AChR}$ degradation rate. Figure 2 shows that very little nonspecific binding is present and that the specific AChR sites (defined as the number of $\alpha$-BGT or ACh binding sites $/ \mu \mathrm{m}^{2}$ ) have a distribution as previously described (Salpeter et al., 1988), with a sharp drop-off away from the $\mathrm{nmj}$, followed by a very gradual decrease in density. The general shape of the grain density distribution, however, remained the same with time after labeling as the AChRs decayed (data not shown). We define the region up to $\sim 50 \mu \mathrm{m}$ from the edge of the $\mathrm{nmj}$ as perijunctional, since this distance delineates the region that has a very steep site-density gradient. Within $50 \mu \mathrm{m}$ from the $\mathrm{nmj}$, the AChR site density drops from the 18,000 sites $/ \mu \mathrm{m}^{2}$, characteristic for the $\mathrm{nmj}$, to $\sim 40$ sites $/ \mu \mathrm{m}^{2}$ (see also Salpeter et al., 1988). As can be seen in Figures 1 and 2, most of this drop occurs in a rim of $\sim 10 \mu \mathrm{m}$ from the nmj. Beyond $50 \mu \mathrm{m}$ from the $\mathrm{nmj}$, the site density decreases more slowly from 40 to $<30$ sites $/ \mu \mathrm{m}^{2}$ by $120 \mu \mathrm{m}$. In the area between 54 and $130 \mu \mathrm{m}$, the average AChR site density is about $33 \mathrm{sites} / \mu \mathrm{m}^{2}$, which allowed for easy analysis of degradation rates (see Fig. 3). Beyond 200 $\mu \mathrm{m}$, the AChR site density drops to very low levels (Salpeter et al., 1988). To establish how characteristic our degradation re-

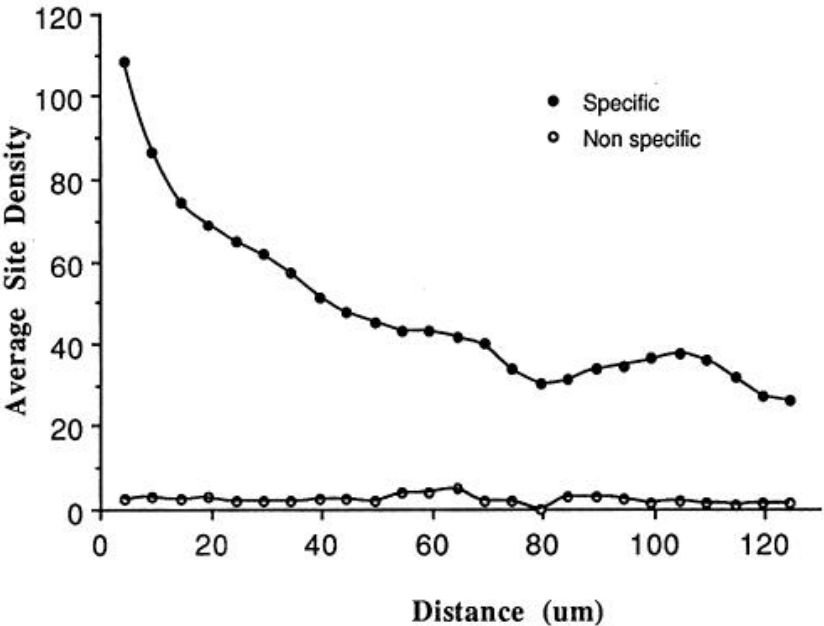

Figure 2. AChR binding site density with distance from edge of $\mathrm{nmj}$. Experimental data were taken from muscles fixed $3 \mathrm{hr}$ after labeling (to be called day 0 ). Nonspecific binding $(\mathrm{O})$ (obtained as described in Materials and Methods) is given by the lower curve and is subtracted from the total counts to give the upper curve of specific label $(\bullet)$. Grains were counted in bins (of $5 \times 5 \mu \mathrm{m}$ ) starting $4.5 \mu \mathrm{m}$ from the edge of the $\mathrm{nmj}$. Data were smoothed as previously described (Salpeter et al., 1988). Beyond the $120 \mu \mathrm{m}$ shown here (where the site density is $\sim 30$ sites $/ \mu \mathrm{m}^{2}$ ), the average random extrajunctional site density obtained from photographs of muscle segments without $\mathrm{nmjs}$ is $\sim 7 \mathrm{sites} / \mu \mathrm{m}^{2}$.

sults from the extrajunctional AChRs within 54-130 $\mu \mathrm{m}$ were, we also determined the site density and degradation of randomly photographed fiber segments and found this random extrajunctional AChR density to be $\sim 7$ sites (or $4 \mathrm{AChR}$ molecules)/ $\mu \mathrm{m}^{2}$. In a mouse sternomastoid muscle fiber of $\sim 0.8 \mathrm{~mm}$ length and 20-30 $\mu$ m diameter, these randomly distributed extrajunctional AChRs represent $\sim 2.2 \times 10^{5} \mathrm{AChR}$ molecules compared to about $10^{5}$ extrajunctional AChR molecules within 54-130 $\mu \mathrm{m}$ from the nmj. Since there are $\sim 2.6 \times 10^{7} \mathrm{AChR}$ molecules at the $\mathrm{nmj}$ of that muscle [obtained by multiplying $2900 \mu \mathrm{m}^{2}$ of dense postjunctional membrane (Matthews-Bellinger and Salpeter, 1978) by $9000 \mathrm{AChR}$ molecules $\left./ \mu \mathrm{m}^{2}\right]$, total extrajunctional AChRs constitute just over $1 \%$ of AChRs in innervated sternomastoid muscle, most of which are at very low density distributed randomly over the muscle fiber.

The degradation half-life for extrajunctional $\mathrm{AChRs}$ averaged over the area from 54 to $130 \mu \mathrm{m}$ from the junction measured $9 \mathrm{~d}$ (Fig. 3), and that for the randomly distributed extrajunctional AChRs measured $7 \mathrm{~d}$. Both degradation $t_{1 / 2}$ values are within the range previously reported for the $\mathrm{R}_{\mathrm{s}} \mathrm{AChRs}$ at innervated nmjs (for reviews, see Fambrough, 1979; Salpeter 1987b) and are not significantly different by $F$ test (performed as previously described; Shyng and Salpeter, 1990).

\section{Discussion}

ScEM autoradiograms of innervated sternomastoid muscles labeled with ${ }^{125} \mathrm{I}-\alpha$-BGT show developed grains in significant numbers (giving $>20$ sites $/ \mu \mathrm{m}^{2}$ ) up to $\sim 130 \mu \mathrm{m}$ from the $\mathrm{nmj}$. The distances from the nmj over which these developed grains are seen is much larger than the $0.1 \mu \mathrm{m}$ resolution half-distance characteristic for ${ }^{125} \mathrm{I}$ under our experimental conditions (Salpeter et al., 1977) and could therefore not be due to radiation spread from the nmj. Furthermore, the fact that the shape of 
the grain distribution did not change with time after labeling signifies that the extrajunctional developed grains could not be due to $A C h R$ diffusion from the $\mathrm{nmj}$. The extrajunctional grains, even those in the gradient around the nmj, must therefore reflect AChRs inserted within the extrajunctional membrane.

This study shows that in innervated mouse sternomastoid muscle, extrajunctional AChRs degrade with an average $t_{\psi}$ of $\sim 8 \mathrm{~d}$ like junctional AChRs do. Since between 54 and $130 \mu \mathrm{m}$ from the nmj the average AChR site density was about 33 sites/ $\mu \mathrm{m}^{2}$ and dropped to an average of $\sim 7$ sites $/ \mu \mathrm{m}^{2}$ over randomly selected extrajunctional areas, we conclude that, as is the case for AChRs at the lower regions of the junctional folds (Salpeter and Harris, 1983), slow degradation does not require high AChR site density. Primarily, however, this study shows that slowly degrading AChRs are not restricted to the postsynaptic membrane of the nerve-muscle contact area. Thus, unlike the conclusion of Rotzler and Brenner (1990) for rat soleus muscle, AChRs do not necessarily require some feature unique to the morphologically defined $\mathrm{nmj}$ to acquire or maintain a stable degradation rate. The degradation of extrajunctional as well as junctional AChRs may indeed depend on the state of innervation of the muscle, and not necessarily on either their location or site density.

Our study does not address the question of whether any rapidly degrading $\left(R_{r}\right)$ AChRs are also expressed at some low concentration in innervated muscles. Such a population has been reported at the innervated $\mathrm{nmj}$ (Bevan and Steinbach, 1983; Stanley and Drachman, 1983) and was also scen in the present study, as can be seen by comparing Figures 2 and 3 . The labeled site density within $54-130 \mu \mathrm{m}$ from the $\mathrm{nmj}$ decays from about 33 to about 22 sites $/ \mu \mathrm{m}^{2}$ between day 0 and day 1 after labeling. It is also possible that a small percentage of $R$ AChRs may account for the slightly shorter measured half-life for random extrajunctional AChRs than for those closer to the $\mathrm{nmj}$. These aspects need further investigation. They do not detract, however, from the finding that in innervated mouse sternomastoid muscle the majority of extrajunctional as well as junctional AChRs are slowly degrading $\left(R_{s}\right) A C h R s$.

The mechanism whereby innervation causes a switch to occur from $R_{r}$ to $R_{s}$ AChRs is not yet known, nor whether it can involve a stabilization of the $R_{r}$ AChRs. Shyng and Salpeter (1990) suggest that the switch from $R_{r}$ to $R_{s}$ occurs after innervation by a downregulation of $R_{r}$ synthesis and a replacement of the $R_{r}$ AChRs by $R_{s}$ AChRs. The possibility that there are two populations of $A C h R s$ with different degradation properties, whose synthesis depends on the state of innervation, is reminiscent of the presence of fetal ( $\gamma$-containing) and adult ( $\epsilon$-containing) AChRs differing in channel conductance (Michina et al., 1986; Witzemann et al., 1987; Gu and Hall, 1988). It is of interest that the adult or high-conductance AChRs are also not restricted to the nmj (Brehm and Kullberg, 1987; Henderson et al., 1987; Brehm and Henderson, 1988), similarly arguing for the need to redefine the concept of junctional versus extrajunctional AChRs. It seems that the terms junctional and extrajunctional AChRs need to be restricted to morphological entities, as they do not appear to include inherent functional distinctions.

Although under steady state conditions [as in the present study for innervated muscle and in Shyng and Salpeter $(1989,1990)$ for chronically denervated muscles] AChRs may have the same degradation rate in the extrajunctional as in the junctional regions, this may not be the case immediately after denervation of adult

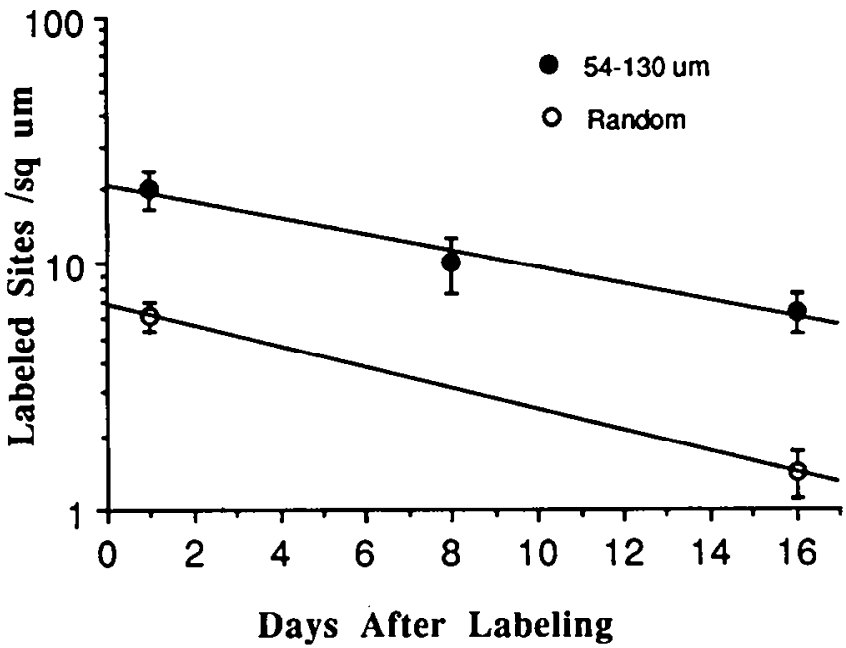

Figure 3. AChR degradation obtained for extrajunctional AChRs averaged over a distance from about $54-130 \mu \mathrm{m}$ from the edge of the nmj (top curve,, ) and at random distances from the $\mathrm{nmj}$ (botlom curve, $\mathrm{O}$ ). AChRs were labeled on day 0 , and the number of labeled AChR sites/ $\mu \mathrm{m}^{2}$ of muscle surface remaining between $1 \mathrm{~d}$ and $16 \mathrm{~d}$ thereafter was tabulated. The data were fit by linear regression to a single exponential. The $t_{1,}$, values were calculated from the slopes and were $9 \mathrm{~d}$ for the AChRs within 54-130 $\mu \mathrm{m}$ from the $\mathrm{nmj}$ and $7 \mathrm{~d}$ for the random AChRs on fiber segments without nmjs.

muscle or after innervation during development. For instance, in mouse sternomastoid muscle, $R_{r}$ AChRs begin to accumulate in extrajunctional regions within 3-4 $d$ after denervation (see review by Salpeter, 1987b), but the degradation rate of the junctional AChRs at the denervated $\mathrm{nmj}$ has not yet increased (Levitt et al., 1980). Since the absolute AChR site density at the $\mathrm{nmj}$ remains relatively constant after denervation (Frank et al., 1975; Loring and Salpeter, 1980; Bader, 1981; Levitt-Gilmour and Salpeter, 1986; Salpeter, 1987a), this delay after denervation could depend on how quickly the $R_{s}$ population of $A C h R$ can degrade and be replaced by the $R_{r}$ AChRs. Of greater interest is a second situation, illustrated in the report by Steinbach et al. (1979), who show that during development the junctional AChRs begin to degrade slowly while extrajunctional AChRs are still degrading rapidly. This delay in the downregulation of $R_{r}$ AChRs at extrajunctional regions while $R_{s}$ AChRs already predominate at the $n m j$ suggests that these two populations of AChRs can be maintained simultaneously in different regions of the muscle. The periods of synaptogenesis or denervation and reinnervation thus provide windows of time for studying the regulation of both $R_{\text {, }}$ and $R_{s}$ AChRs. Similarly, the fact that in innervated muscle there are extrajunctional $R_{\mathrm{s}}$ AChRs at densities of $>30$ sites $/ \mu \mathrm{m}^{2}$ for at least $120 \mu \mathrm{m}$ beyond the $\mathrm{nmj}$ (present study) provides a nonjunctional region of muscle in which many slowly degrading AChRs are either synthesized or stabilized and anchored in the membrane. These windows in time and space provide useful constraints in the study of the mechanisms determining AChR turnover and should allow us to determine the characteristics that are unique for the $R_{s}$ and $\mathrm{R}_{\mathrm{r}} \mathrm{AChRs}$.

\section{References}

Bader D (1981) Density and distribution of $\alpha$-bungarotoxin binding sites in postsynaptic structures of regenerated rat skeletal muscle. J Cell Biol 88:338-345. 
Berg DK, Hall ZW (1975) Loss of $\alpha$-bungarotoxin from junctional and extrajunctional acetylcholine receptors in rat diaphragm in vivo and in organ culture. J Physiol (Lond) 252:771-789.

Bevan S, Steinbach JH (1983) Denervation increases the degradation rate of acetylcholine receptors at end-plates in vivo and in vitro. J Physiol (Lond) 336:159-177.

Brehm P, Henderson L (1988) Regulation of acetylcholine receptor channel function during development of skeletal muscle. Dev Biol 129:1-11.

Brehm P, Kullberg R (1987) Acetylcholine receptor channels on adult mouse skeletal muscle are functionally identical in synaptic and nonsynaptic membrane. Proc Natl Acad Sci USA 84:2550-2554.

Brett RS, Younkin SG, Konieczkowski M, Slugg RM (1982) Accelerated degradation of junctional acetylcholine receptor- $\alpha$-bungarotoxin complexes in denervated rat diaphragm. Brain Res 233:133142.

Desaki J, Uehara Y (1981) The overall morphology of neuromuscular junction as revealed by scanning electron microscopy. J Neurocytol 10:101-110.

Fambrough D (1979) Control of acetylcholine receptors in skeletal muscle. Physiol Rev 59:165-227.

Fertuck HC, Salpeter MM (1976) Quantitation of junctional and extrajunctional acetylcholine receptors by electron microscope autoradiography after I-125- $\alpha$-bungarotoxin binding at mouse neuromuscular junctions. J Cell Biol 69:144-158.

Fertuck HC, Woodward WW, Salpeter MM (1975) In vivo recovery of muscle contraction after $\alpha$-bungarotoxin binding. J Cell Biol 66: 209-213.

Frank E, Gautvik K, Sommerschild H (1975) Persistence of junctional AChR following denervation. Cold Spring Harbor Symp Quant Biol 40:275-281.

Gu Y, Hall ZW (1988) Immunological evidence for a change in subunits of the acetylcholine receptor in developing and denervated rat muscle. Neuron 1:117-125.

Hendersen LP, Leichleiter J, Brehm P (1987) Single channel properties of newly synthesized acetylcholine receptors following denervation of mammalian skeletal muscle. J Gen Physiol 89:999-1014.

Levitt TA, Salpeter MM (1981) Denervated endplates have a dual population of junctional acetylcholine receptors. Nature 291:239241.

Levitt TA, Loring RH, Salpeter MM (1980) Neuronal control of acetylcboline receptor turnover rate at a vertebrate neuromuscular junction. Science 210:550-551.

Levitt-Gilmour TA, Salpeter MM (1986) Gradient of extrajunctional acetylcholine receptors after denervation of mammalian muscle. J Ncurosci 6:1606-1612.

Loring R, Salpeter MM (1980) Denervation increases turnover rate of junctional acetylcholine receptors. Proc Natl Acad Sci USA 77: 2293-2298.
Matthews-Bellinger JA, Salpeter MM (1978) Distribution of acetylcholine receptors at frog neuromuscular junctions with a discussion of some physiological implications. J Physiol (Lond) 279:197-213.

Michina M, Takai T, Imoto K, Noda M, Takahashi T, Numa S, Methfessel C, Sakmann B (1986) Molecular distinction between fetal and adult forms of muscle acetylcholine receptor. Nature 321:406 -411.

Rotzler S, Brenner HR (1990) Metabolic stabilization of acetylcholine receptors in vertebrate neuromuscular junction by muscle activity. $\mathrm{J}$ Cell Biol 111:655-661.

Salpeter MM (1987a) Vertebrate neuromuscular junctions: general morphology, molecular organization, and functional consequences. In: The vertebrate neuromuscular junction (Salpeter MM, ed), pp I54. New York: Liss.

Salpeter MM (1987b) Development and neural control of the neuromuscular junction and of the junctional acetylcholine receptor. In: The vertebrate neuromuscular junction (Salpeter MM, ed), pp 55115. New York: I iss.

Salpeter MM, Harris R (1983) Distribution and turnover rate of acetylcholine receptors throughout the junction folds at a vertebrate neuromuscular junction. J Cell Biol 96:1781-1785.

Salpeter MM, Fertuck HC, Salpeter EE (1977) Resolution in electron microscope autoradiography. III. Iodine- 125 , the effect of heavy metal staining and a reassessment of critical parameters. J Cell Biol 72:161173.

Salpeter MM, Marchaterre M, Harris R (1988) Distribution of extrajunctional acetylcholine receptors on a vertebrate muscle: evaluated by using a scanning electron microscope autoradiographic procedure. J Cell Biol 106:2087-2093.

Shyng S-L, Salpeter MM (1989) Degradation rate of acetylcholine receptors inserted into denervated vertebrate neuromuscular junctions. J Cell Biol 108:647-651

Shyng S-L, Salpeter MM (1990) Effect of reinnervation on the degradation rate of junctional acetylcholine receptors synthesized in denervated skeletal muscles. J Neurosci 10:3905-3915.

Shyng S-L, Xu R, Salpeter MM (1991) Cyclic AMP stabilizes the degradation of original junctional acetylcholine receptors in denervated muscle. Neuron 6:469-475.

Stanley EF, Drachman DB (1981) Denervation accelerates the degradation of junctional acetylcholine receptors. Exp Neurol 73:390 396.

Stanley EF, Drachman DB (1983) Rapid degradation of "new" acetylcholine receptors at neuromuscular junctions. Science 222:67-69.

Steinbach JH, Merlie J, Heinemann S, Bloch R (1979) Degradation of junctional and extrajunctional acetylcholine receptors by developing rat skeletal muscle. Proc Natl Acad Sci USA 76:3547-3551.

Witzemann V, Barg B, Nishikawa Y, Sakmann B, Numa S (1987) Differential regulation of muscle acetylcholine receptor $\gamma$ - and $\epsilon$-subunit mRNAs. FEBS Lett 223:104-112. 